\title{
Analysis of the detection coefficient for the association between leprosy and pregnancy in the integration region of Carajás, State of Pará, Brazil
}

\author{
Vera Regina da Cunha Menezes Palácios ${ }^{[1]}$, Cléa Nazaré Carneiro Bichara ${ }^{[1]}$, \\ Rodrigo da Silva Dias ${ }^{[1]}$, Alcinês da Silva Sousa Júnior ${ }^{[2]}$, Renan Faria Cardoso ${ }^{[3]}$, \\ Glaubus Vinicius Neves Barreiros ${ }^{[2]}$ and Nelson Veiga Gonçalves ${ }^{[1],[2],[4]}$
}

[1]. Departamento de Saúde Comunitária, Universidade do Estado do Pará, Belém, PA. [2]. Laboratório de Geoprocessamento, Instituto Evandro Chagas, Ananindeua, PA. [3] Curso de Medicina, Universidade do Estado do Pará, Belém, PA. [4]. Laboratório de Geoprocessamento, Universidade do Estado do Pará, Belém, PA.

\begin{abstract}
Introduction: The association between leprosy and pregnancy is currently poorly understood and has been linked to serious clinical consequences. Methods: A retrospective study between 2007 and 2009 was performed in the integration region of Carajás, Brazil on a population of pregnant lepers, with non-lepers of ages 12-49 years serving as the reference population. Results: Twenty-nine pregnant lepers were studied during the study period. The detection rates (DRs) for the studied association were 4.7 in 2007, 9.4 in 2008, and 4.3 in 2009. Conclusions: The Carajás region presented a medium pattern of endemicity during most of the study period, with a high DR found in 2008 .
\end{abstract}

Keywords: Leprosy. Pregnancy. Epidemiology.

According to the World Health Organization (WHO), 244,796 cases of leprosy were detected in 2009 , which represents a decreased detection rate since $2003^{1}$.

The WHO currently uses an operational classification to register leprosy cases based on clinical and bacteriological indices ${ }^{2,3}$. According to the Jopling classification (1966), leprosy reactions are divided into type I (reverse) and type II reactions and are present in $10-50 \%$ of cases, especially in multibacillary forms, thus constituting a risk factor for disability ${ }^{4}$.

In Brazil, data on leprosy during pregnancy have only been reliably available since 2007 from the Information System for Notifiable Diseases (SINAN) ${ }^{5,6}$, which reduces and limits the data that can be analyzed.

During pregnancy, cellular immunity is suppressed, particularly in the last quarter of pregnancy. Additionally, in the puerperium phase, humoral immunity is suppressed, which explains why pregnant women are more susceptible to infections, such as hepatitis and toxoplasmosis ${ }^{7-9}$.

Leprosy reactions may arise before, during, or after leprosy treatment ${ }^{9}$. Type II reactions occur mainly in the last trimester of pregnancy and may even lead to Lucio's phenomenon (necrotizing vasculitis $)^{8,10}$. This study aimed to analyze the association between

\footnotetext{
Address to: Dra. Vera Regina da Cunha Menezes Palácios. Travessa Rui Barbosa 619/1102, Bairro do Reduto, 66053-260 Belém, PA, Brasil.

Phone: 5591 9983-3013.

e-mail: verareginapalacios@gmail.com

Received 20 November 2011

Accepted 19 February 2012
}

leprosy and pregnancy, as well as update the epidemiological records of this interaction, using the current methods of data collection for the generation of detection rates (DRs). The objective was to review the process of data generation.

To achieve this aim, we performed a retrospective investigation of the DRs for the period of 2007 to 2009, in the integration region of Carajás, State of Pará, Brazil (Figure 1), after applying the formula for calculating the DR of the number of cases of leprosy in pregnant subjects by region of integration in Pará (Table 1). To calculate the DRs of leprosy associated with pregnancy, the number of pregnant leper women was divided by the size of the female population between 12 and 49 years of age (childbearing age) and multiplied by 100,000 . The coefficient generated allowed us to analyze the strength of the association between leprosy and pregnancy, as well as its magnitude and trend. As the Carajás region showed the highest DRs, we performed a detailed analysis of its municipalities (Table 2). The collection of variables of interest related to the study population and reference population was performed from data provided by the Department of Informatics of SUS (DATASUS), as well as from data on the SINAN notification forms and on the population database from the Brazilian Institute of Geography and Statistics (IBGE).

Because there is no suitable parameter for the association between leprosy and pregnancy, the significance of the observed DRs was assessed by comparing the DR findings with the overall detection rate recommended by the Ministry of Health (MS) ${ }^{11,12}$. Specifically, for every 100,000 inhabitants, hyperendemic indicates greater than or equal to 40 cases, very high indicates 20-39 cases, high indicates 10-19 cases, medium indicates 2-9 cases, and low indicates less than 2 cases. 


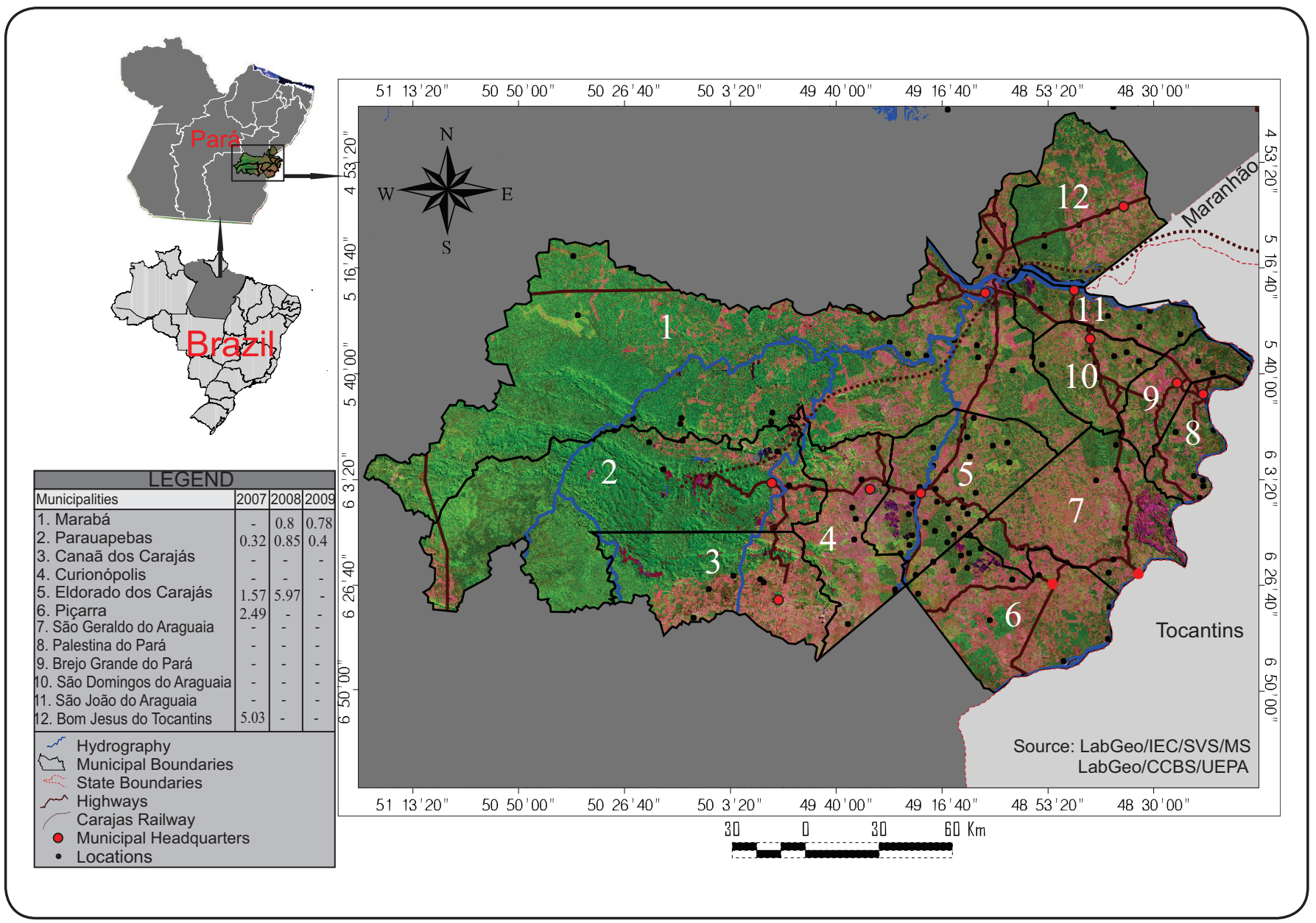

FIGURE 1 - Spatial distribution of the detection rates for the association between leprosy and pregnancy in the integration region of Carajás, State of Pará, Brazil. LabGeo: Laboratório de Geoprocessamento; IEC: Instituto Evandro Chagas; MS: Ministério da Saúde, CCBS: Centro Ciências Biológicas e da Saúde, UEPA: Universidade Estadual do Pará.

TABLE 1 - Detection rates for the association between leprosy and pregnancy by integration region, State of Pará, Brazil, between 2007 and 2009.

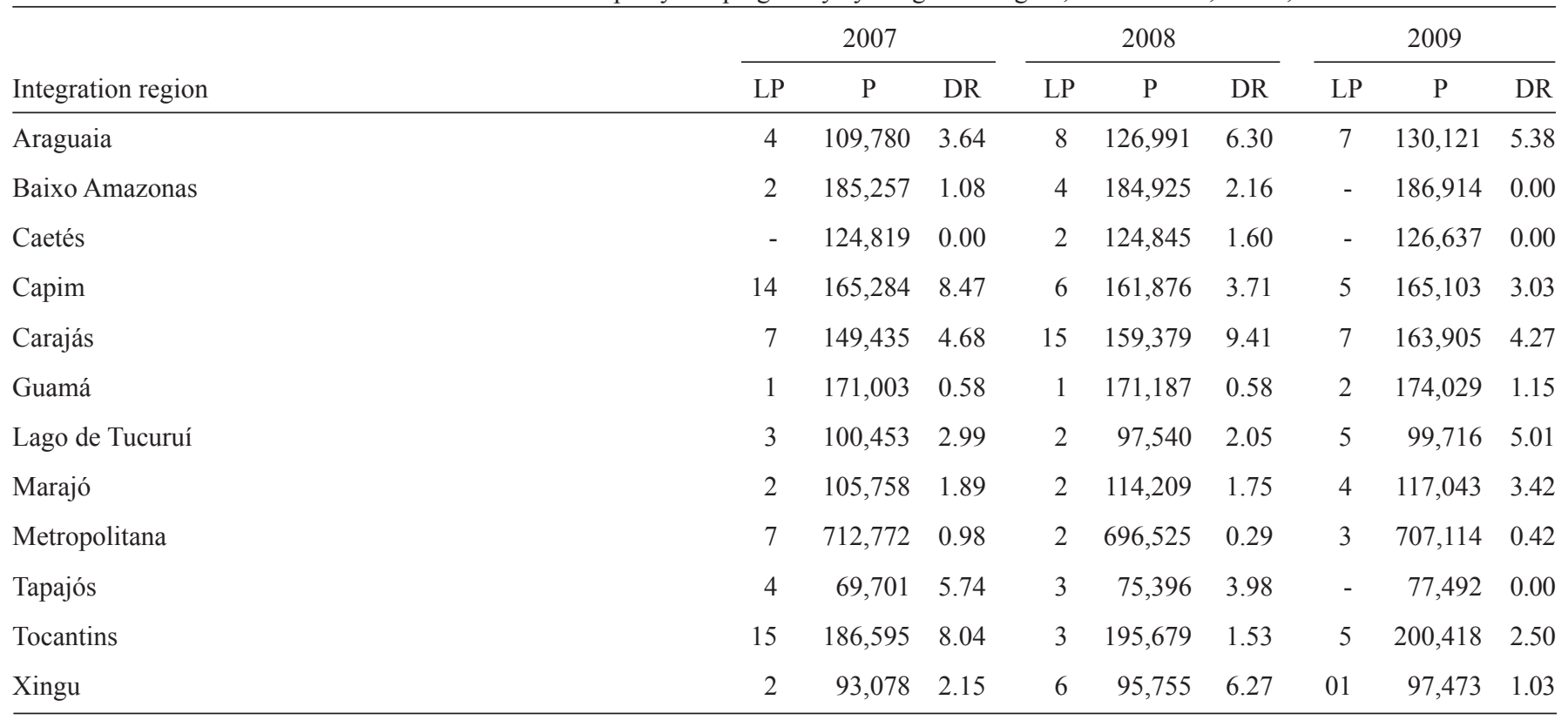

LP: number of leper pregnants; P: female population between 12 and 49 years old; DR: detection rate of the number of cases. *Per 100,000 inhabitants. Source: Departamento de Informática do Sistema Único de Saúde (DATASUS) and Instituto Brasileiro de Geografia e Estatística (IBGE). 
TABLE 2 - Number of women of childbearing age, number of cases of pregnant lepers, and the detection rates by municipality in Carajás, State of Pará, Brazil.

\begin{tabular}{|c|c|c|c|c|c|c|c|c|c|}
\hline Municipality & \multicolumn{3}{|c|}{ Women of childbearing age } & \multicolumn{3}{|c|}{ Pregnant lepers } & \multicolumn{3}{|c|}{ Detection rate* } \\
\hline Canaã dos Carajás & 4,281 & 7,866 & 8,388 & 0 & 0 & 0 & 0 & 0 & 0 \\
\hline Curionópolis & 3,612 & 5,075 & 5,041 & 0 & 0 & 0 & 0 & 0 & 0 \\
\hline Eldorado dos Carajás & 12,769 & 8,371 & 8,419 & 2 & 5 & 0 & 1.57 & 5.97 & 0 \\
\hline Palestina do Pará & 2,509 & 1,995 & 1,997 & 0 & 0 & 0 & 0 & 0 & 0 \\
\hline Parauapebas & 31,652 & 46,858 & 49,556 & 1 & 4 & 2 & 0.32 & 0.85 & 0.4 \\
\hline Piçarra & 4,023 & 3,620 & 3,651 & 1 & 0 & 0 & 2.49 & 0 & 0 \\
\hline São João do Araguaia & 5,019 & 3,361 & 3,367 & 1 & 1 & 0 & 1.99 & 2.98 & 0 \\
\hline São Geraldo do Araguaia & 7,819 & 7,311 & 7,266 & 0 & 0 & 0 & 0 & 0 & 0 \\
\hline Total** & 149,435 & 159,379 & 163,905 & 7 & 15 & 7 & 4.68 & 9.41 & 4.27 \\
\hline
\end{tabular}

*Per 100,000 inhabitants; **Detection rate calculated relative to the entire region of Carajás.

According to the general parameter for the DRs studied, the following results were obtained, as detailed in Table 1: high (Carajás in 2008), medium (Araguaia every year, Baixo Amazonas in 2008, Capim every year, Carajás in 2007 and 2009, Lago de Tucuruí every year, Marajó in 2009, Tapajos in 2007 and 2008, Tocantins in 2007 and 2009, and Xingu in 2007 and 2008), and low (Caetés, Guamá, and Metropolitana in all years). The Carajás region presented a medium pattern of endemicity in other years of research.

Because these study data only take into account the size of the female population between 12 and 49 years of age, which is a fraction of the general population, it was observed that the DRs, compared with the parameter recommended by the Ministry of Health, may not reflect the actual epidemiological situation of the studied interaction. Therefore, it was necessary to identify a more appropriate parameter, such as the parameter used for children under 15 years of age, which is also a population fragment.

The analysis shows that the region of Carajás had the highest DR in the State of Pará, ranging from medium to high throughout the study period. Considering the differentiated demographic and socioeconomic characteristics of this region, a spatial trend analysis will be carried out throughout this ongoing study to better understand the social influences on the association between leprosy and pregnancy. After this analysis was performed, the need for identifying a new parameter for assessing the DR of pregnant lepers was realized, as neither the general population size nor the number of children under 15 years of age proved to be adequate. The number of pregnant women affected by leprosy is much lower than the general population size and the number of children under 15 years of age. Only with a new parameter will it be possible to reliably assess the strength of the association of interest, often associated with clinical outbreaks of leprosy or with the worsening of the disease, as well as its actual magnitude and trend. This parameter will be the subject of future reports as the work of this research group continues.

\section{ACKNOWLEDGMENTS}

The authors thank Mr. Sebastião Alves de Sena Neto (Sistema Nacional de Agravos de Notificação/MS) for his invaluable help with this research.

\section{CONFLICT OF INTEREST}

The authors declare that there is no conflict of interest.

\section{REFERENCES}

1. World Health Organization (WHO). Weekly Epidemiological Record [Internet]. Geneva: WHO; 2010 August 27 [Cited 2010 December 25]. p. 337-348. Available from: http://www.who.int/wer/2010/wer8535/ en/index.html

2. Lockwood D. Leprosy. BMJ [Internet]; 2007. [Cited 2010 September 15]. Available from: http://clinicalevidence.bmj.com/ceweb/conditions/ ind/0915/0915_backgr.jsp/

3. Croft RP, Smith WCS, Nicholls P, Richardus JH. Sensitivity and specificity of methods of classification of leprosy without use of skin-smear examination. Int J Lepr Other Mycobact Dis 1998; 66:445-450.

4. Teixeira MAG, Silveira VM, França ER. Características epidemiológicas e clínicas das reações hansênicas em indivíduos paucibacilares e multibacilares 
atendidos em dois centros de referência para hanseníase, na cidade de Recife, Estado de Pernambuco. Rev Soc Bras Med Trop 2010; 43:287-292.

5. Galvão PRS, Ferreira AT, Maciel MGG, Almeida RP, Hinders D, Schreuder PA, et al. Uma avaliação do sistema de informação SINAN usado no Programa de Controle de Hanseníase no estado do Pernambuco, Brasil. Cad Saúde Coletiva 2009; 17:87-102.

6. Ministério da Saúde. Portal da Saúde. Hanseníase - Casos confirmados notificados no Sistema de Informação de Agravos de Notificação [Internet]. Brasília: Departamento de Informática do SUS; 2009 [Cited 2010 September 12]. Available from: http://dtr2004.saude.gov.br/sinanweb/ tabnet/dh?sinannet/hanseniase/bases/Hansbrnet.def/

7. Lockwood DN, Sinha HH. Pregnancy and leprosy: a comprehensive literature review. Int J Lepr Other Mycobact Dis 1999; 67:6-12.

8. Helmer KA, Fleischfresser I, Kucharski-Esmanhoto LD, Fillus Neto J, Santamaria JR. Lucio's phenomenon (necrotizing erythema) in pregnancy. An Bras Dermatol 2004; 79:205-210.
9. Ministério da Saúde. Brasil reduz casos de hanseníase em menores de 15 anos SVS em rede [Internet]. Brasília: Secretaria de Vigilância em Saúde; 2010 [Cited 2010 September 12]. Available from: http://189.28.128.179:8080/ svs_informa/edicao-69-janeiro-de-2010/brasil-reduz-casos-de-hanseniaseem-menores-de-15-anos/

10. Rodríguez-Pazos L, Gómez-Bernal S, Sánchez-Aguilar D, Toribio J. Lepra Reaction and Pregnancy. Actas Dermosifiliogr 2010; 101:190-191.

11. Ministério da Saúde, Secretaria de Vigilância em Saúde, Departamento de Vigilância Epidemiológica. Programa Nacional de Eliminação da Hanseníase. In: Ministério da Saúde, editor. Hanseníase. Guia de Vigilância Epidemiológica. $7^{\text {th }}$ ed. Brasília: Ministério da Saúde; 2009. p. 1-28.

12. Palácios VRCM, Dias RS, Neves DCO. Estudo da situação da hanseníase no estado do Pará. Rev Para Med 2010; 24:49-56. 